\title{
Diagnostic Value of Serum Insulin-Like Growth Factor Binding Protein 7 (IGFBP7) in Colorectal Cancer
}

\author{
Bo Qiu',* \\ Ling-Yu Chu (iD) $2,3, *$ \\ Xin-Xin $\mathrm{Li}^{4}$ \\ Yu-Hui Peng 2,3 \\ Yi-Wei Xu (D) ${ }^{2,3}$ \\ Jian-Jun Xie (iD ${ }^{3,5}$ \\ Xiao-Yang Chen iD ${ }^{6}$ \\ 'Department of Pathology, Medical \\ College of Jiaying University, Meizhou, \\ People's Republic of China; ${ }^{2}$ Department \\ of Clinical Laboratory Medicine, The \\ Cancer Hospital of Shantou University \\ Medical College, Shantou, People's \\ Republic of China; ${ }^{3}$ Precision Medicine \\ Research Center, Shantou University \\ Medical College, Shantou, People's \\ Republic of China; ${ }^{4}$ Department of \\ Surgery, The First Affiliated Hospital of \\ Shantou University Medical College, \\ Shantou, People's Republic of China; \\ ${ }^{5}$ Department of Biochemistry and \\ Molecular Biology, Shantou University \\ Medical College, Shantou, People's \\ Republic of China; ${ }^{6}$ Department of \\ Pediatric, The First Affiliated Hospital of \\ Shantou University Medical College, \\ Shantou, People's Republic of China \\ *These authors contributed equally to \\ this work
}

Correspondence: Xiao-Yang Chen; Jian-Jun Xie Email cxycxd2000@sina.com; g_jixie@stu.edu.cn
This article was published in the following Dove Press journal: OncoTargets and Therapy

Purpose: High serum insulin-like growth factor binding protein-7 (IGFBP-7) has been found in several malignant tumors. Here, we aimed to assess the diagnostic potential of serum IGFBP7 in patients with colorectal cancer (CRC).

Patients and Methods: An enzyme-linked immunosorbent assay (ELISA) was performed to detect IGFBP7 level in the serum of 115 CRC patients and 107 healthy controls, and receiver operating characteristics (ROC) was used to evaluate the accuracy of diagnosis.

Results: The levels of serum IGFBP7 were significantly higher in CRC than those in normal controls $(P<0.001)$. With optimized cutoff of $2.050 \mathrm{ng} / \mathrm{mL}$, IGFBP7 showed certain diagnostic value with specificity of $93.9 \%$, sensitivity of $64.5 \%$ and an area under the curve (AUC) of 0.815 (95\% CI: 0.754-0.877) in CRC. In early-stage CRC, IGFBP7 provided an AUC of 0.826 (95\% CI: 0.757-0.896), a sensitivity of $64.5 \%$, and a specificity of $95.8 \%$. Furthermore, when compared with carcinoembryonic antigen (CEA), the accuracy of serum IGFBP7 in the diagnosis of CRC and early-stage CRC were significantly improved. Analysis of clinical data shows that there are no significant differences between IGFBP7 and clinical factors.

Conclusion: Our study suggested that serum IGFBP7 might serve as a potential biomarker for early-stage CRC diagnosis.

Keywords: colorectal cancer, IGFBP7, serum, biomarker, diagnosis

\section{Introduction}

Colorectal cancer (CRC) is one of the most serious malignancies, for it ranks third in terms of incidence but second in terms of mortality. ${ }^{1}$ There was an estimated 1.8 million new CRC cases and 881,000 CRC-related death cases occurred in 2018. ${ }^{1}$ There is a higher incidence and mortality in females than that in males in worldwide. ${ }^{1,2}$ The geographic areas with highest incidence are located in Europe, Australia/New Zealand, Northern America, and Eastern Asia. ${ }^{1}$ Due to the absence of typical symptoms in patients with early stage diseases, CRC tends to present at an advanced stage at diagnosis. ${ }^{3}$ For patients with early-stage CRC, the 5-year survival rate probability is as high as $90 \% ;{ }^{4}$ however, this proportion declines to about $20 \%$ in patients with an advanced stage CRC. ${ }^{5}$ Therefore, exploring an effective and reliable method to identify CRC at an early stage is the key to improve the survival of patients with this disease.

Studies have shown that CRC is not a sudden lesion of the colonic mucosa, but is developed through a series of "normal mucosal-adenomas". ${ }^{6}$ Due to the slow and 
gradual development of the disease, it is generally agreed that most of this disease is preventable and can be cured by early detection and removal of precancerous polyps or early tumors. ${ }^{7}$ Therefore, early detection of CRC is critical to reduce morbidity and mortality associated with the disease. At present, the most widely used diagnostic methods of CRC are endoscopy and $\mathrm{CT}^{8},{ }^{8}$ however, these are expensive to implement, complicated to operate, time consuming and invasive, which limits application in clinical screening. ${ }^{9}$ Thus, it is necessary to develop a simpler and less invasive detection method to improve the diagnosis rate of CRC. Moreover, the detection of tumor markers has been widely used in the early screening and diagnosis of cancer. ${ }^{10}$ Carcinoembryonic antigen (CEA) is the most widely used tumor marker in clinical treatment of CRC and has limited sensitivity and specificity. ${ }^{11,12}$ Therefore, we aim to explore a more ideal CRC marker in this study and explore its value in early diagnosis of CRC.

Insulin-like growth factor binding protein-7 (IGFBP-7), also known as tumor adhesion factor and Vasomodulin, is a secreted protein and one of multiple IGFBP-related proteins. ${ }^{13}$ As an important binding protein for insulin-like growth factor, IGFBP7 is widely distributed in the body and plays an important role in regulating insulin distribution and cell proliferation, differentiation, and growth. ${ }^{14}$ IGFBP7 is the protein with the strongest binding capacity to insulin among the members of the IGFBPs family discovered so far. Compared with IGFBP1-6, its binding capacity to insulin is 500 times stronger. ${ }^{15}$ IGFBP7 protein binds to insulin with high affinity, so that insulin cannot bind to its receptor, thereby inhibiting insulin-stimulated autophosphorylation of insulin receptor $\beta$ subunit and phosphorylation of insulin receptor substrate I (IRS-1), causing Insulin resistance. ${ }^{16,17}$ It has been reported that the expression of IGFBP7 is closely related to cancers such as lung cancer, prostate cancer, esophageal squamous cell carcinoma (ESCC) and esophagogastric junction adenocarcinoma (EJA). ${ }^{18-21}$ However, the relationship between serum IGFBP7 and CRC, especially its diagnostic value, has been rarely reported. This study combines the non-invasive characteristics to explore the diagnostic value of serum IGFBP7 in CRC, with a view to provide an ideal indicator for CRC detection.

\section{Patients and Methods}

\section{Study Samples}

In this study, 115 serum samples of CRC patients were collected from the First Affiliated Hospital of Shantou
University Medical College, from September 2013 to October 2018. One hundred and seven normal controls were selected from the Cancer Hospital of Shantou University Medical College, from May 2015 to February 2017. CRC serum samples were all newly diagnosed patients without any anti-cancer treatment before blood collection. Healthy controls were qualified blood donors with no evidence of cancers.

The patients included in the analysis met the following criteria: (1) were diagnosed as CRC by histopathological examination; (2) had no cancer or received any anti-cancer treatment before the diagnosis of CRC; (3) received chest CT examination, which can be excluded Lung metastases; (4) have complete follow-up data. Cancer patients who did not meet the above criteria were excluded. The inclusion criteria for normal people are healthy blood donors without $\mathrm{CRC}$ or any other cancers.

After venous sampling, the peripheral blood samples of patients and controls were collected by centrifugation with $2500 \mathrm{~g}$ for 10 minutes, and then stored at $-80{ }^{\circ} \mathrm{C}$ until the start of the experiment. By signing informed consent, all patients and normal controls agreed to participate in the study. It was approved by the institutional review board of the Cancer Hospital of Shantou University Medical College (ethical approval number: 2,015,042,419; data: April 24, 2015) and the First Affiliated Hospital of Shantou University Medical College (ethical approval number: 2,018,064; data: August 28, 2018), and conformed to the requirements of the Declaration of Helsinki.

We defined the CRC staging according to the eighth edition of the American Joint Committee on Cancer (AJCC) Cancer Staging Manual. ${ }^{22}$ In this study, we define the 0+I+IIA stage of AJCC TNM as early-stage, and the IIB+III+IV stage as advanced-stage.

\section{Analysis of Serum IGFBP7 and CEA Levels}

The levels of Serum IGFBP7 were detected by ELISA Kit (Cusabio, CSB-E17249h, Wuhan, China). The minimum detectable dose of human IGFBP7 is typically less than $19.5 \mathrm{pg} / \mathrm{mL}$. This assay has high sensitivity and specificity for detection of human IGFBP7. No significant crossreactivity or interference between human IGFBP7 and analogues was observed. ELISA protocol was performed according to the user manual. Briefly, follow the instructions to prepare reagents, samples, and standards. We diluted the sample by a ratio of $1: 3$. The concentrations 
of the IGFBP7 standard curve were $0 \mathrm{pg} / \mathrm{mL}, 78 \mathrm{pg} / \mathrm{mL}$, $156 \mathrm{pg} / \mathrm{mL}, 312 \mathrm{pg} / \mathrm{mL}, 625 \mathrm{pg} / \mathrm{mL}, 1250 \mathrm{pg} / \mathrm{mL}, 2500 \mathrm{pg} /$ $\mathrm{mL}$, and $5000 \mathrm{pg} / \mathrm{mL}$, respectively. After preparation, $100 \mu \mathrm{L}$ standard and serum samples were added to each well and then incubated for 2 hours at $37^{\circ} \mathrm{C}$. Next, removing the liquid without washing, $100 \mu \mathrm{L}$ Biotin-antibody (1X) was added in per well, and then incubated at $37^{\circ} \mathrm{C}$ for 1 hour. Then, wash the plate 3 times with a microplate washer (Microplate washer 888, Thermo Fisher Scientific, Vantaa). One hundred microliter HRP-avidin (1X) was added to the plates and incubated at $37^{\circ} \mathrm{C}$ for 1 hour. Finally, after 5 washes, $90 \mu \mathrm{l}$ of TMB substrate was added to each well and then incubated at $37^{\circ} \mathrm{C}$ for 20 minutes. Within 5 minutes after adding the stop solution, read the OD values at $450 \mathrm{~nm}$ and $570 \mathrm{~nm}$ wavelengths (Multiskan ELX800, BioTek Instruments, Winooski). A four-parameter logistic curve was used to draw a standard curve and multiplied by the dilution factor to obtain the serum IGFBP7 concentration. All serum samples were tested in duplicate, and the mean value was taken for analysis.

The serum levels of CEA were quantified using a UniCel DXi 800 Analyzer and E601. According to the manufacturer's instructions, the cutoff values for normal CEA in the First Affiliated Hospital of Shantou University Medical College and the Cancer Hospital of Shantou University Medical College are less than $9.7 \mathrm{ng} / \mathrm{mL}$ and $3.5 \mathrm{ng} / \mathrm{mL}$, respectively. The level of each CEA in each studied subject was then discretized to one, when it was larger than the corresponding optimal cutoff; otherwise, it was discretized to zero.

\section{Statistical Analysis}

Statistical analysis was performed using GraphPad Prism 8.0 software, SPSS (version 19.0) and Microsoft Excel. When estimating the sample size, we set the standard deviations of the two treatments to be equal, and require the probability of $\alpha=0.05$ and $\beta=0.10$ to be able to discern that the difference between the two increases is $45 \%$ of the standard deviation, that is, $\delta / \sigma=0.45$. The specific calculation formula is $\mathrm{n} 1=\mathrm{n} 2=2\left[\left(\mu_{\alpha}+\mu_{\beta}\right) /(\delta / \sigma)\right]^{2}+\mu_{\alpha}{ }^{2} / 4$. It is known that $\delta / \sigma=0.45$, two-sided $\alpha=0.05, \mu_{\alpha}=1.96, \beta=0.10$, $\mu_{\beta}=1.282$, and the formula is $\mathrm{n} 1=\mathrm{n} 2=2[(1.96+1.282) /$ $(0.45)]^{2}+1.96^{2} / 4 \approx 105$. Therefore, the sample size required for the CRC group and the normal control group are both 105 cases. Combined with the actual sample size collected, the final CRC group has 115 cases and the normal control group 107 cases. The non-parametric Mann-Whitney's
$U$-test was used to analyze the differences of serum IGFBP7 and CEA levels between CRC group, earlystage CRC group and the control group. Results were expressed as mean \pm SDs. The receiver operating characteristic (ROC) analysis was used to assess the diagnostic boundaries, including the area under the ROC curve (AUC), 95\% confidence interval (CI), sensitivity and specificity. The optimum cut-off value was obtained from the Youden's index of the ROC curve, which was the maximum values of sensitivity $+(100 \%$ - specificity $){ }^{23}$ The significant difference between serum IGFBP7 expression and clinicopathological parameters was assessed using a $\chi^{2}$ test. When $P<0.05$, statistically significant differences were confirmed.

\section{Results}

\section{Serum Level of IGFBP7 Increased in CRC Patients}

To evaluate the diagnostic potential of IGFBP7, 222 serum samples were tested, including CRC patients $(n=115)$ and normal controls $(n=107)$. The patient group were consisted of 68 males and 47 females, aged between 27 and 86 (mean, 63 years). There were 113 males and 32 females in the control group, ranging in age from 40 to 80 years (mean, 56 years) (Table 1). Figure 1 shows the IGFBP7 distribution of CRC and normal controls. As can be seen from Figure 1, CRC group occupies more histogram volume at high concentrations, while the normal group occupies more histogram volume at low concentrations. The levels of IGFBP7 (mean \pm SD) were $2.679 \pm 0.480$ $\mathrm{ng} / \mathrm{mL}, 2.683 \pm 0.417 \mathrm{ng} / \mathrm{mL}$ and $1.932 \pm 0.820 \mathrm{ng} / \mathrm{mL}$ in $\mathrm{CRC}$, early-stage CRC and normal control, respectively (Table 2). Compared with the normal control group, IGFBP7 increased not only in the serum of patients with $\mathrm{CRC}$, but also in the serum of patients with early-stage CRC $(P<0.001)$ (Figure 2$)$.

\section{Diagnostic Capacity of IGFBP7 and a Combination of IGFBP7 and CEA in CRC and Early-Stage CRC}

We generated a ROC curve to assess the diagnostic ability of serum IGFBP7 in CRC. According to the ROC curve, the optimized cut-off value for CRC was $2.050 \mathrm{ng} / \mathrm{mL}$. With this cut-off value, IGFBP7 has a certain diagnostic efficacy for CRC, of which AUC is 0.815 (95\% CI:0.754-0.877), sensitivity is $93.9 \%$ and specificity is $64.5 \%$. The AUC of CEA to distinguish CRC patients 
Table I Participant Information and Clinicopathological Characteristics

\begin{tabular}{|c|c|c|}
\hline Group & $\begin{array}{l}\text { CRC Patient } \\
(n=|| 5)\end{array}$ & $\begin{array}{l}\text { Normal Controls } \\
(n=107)\end{array}$ \\
\hline \multicolumn{3}{|l|}{ Age(years) } \\
\hline Mean \pm SD & $63 \pm 11$ & $56 \pm 11$ \\
\hline Range & $27-86$ & $40-80$ \\
\hline \multicolumn{3}{|l|}{ Gender } \\
\hline Male & 68 & 113 \\
\hline Female & 47 & 32 \\
\hline \multicolumn{3}{|l|}{ Tumor size } \\
\hline Mean \pm SD & $4.8 \pm 2.1$ & \\
\hline Range & $1.5-13$ & \\
\hline \multicolumn{3}{|l|}{ Histological grade } \\
\hline High(gradel) & 1 & \\
\hline Middle(grade2) & 92 & \\
\hline Low(grade3) & I & \\
\hline Unknown & 21 & \\
\hline \multicolumn{3}{|l|}{ Depth of tumor } \\
\hline \multicolumn{3}{|l|}{ invasion } \\
\hline $\mathrm{TI}$ & 2 & \\
\hline $\mathrm{T} 2$ & 13 & \\
\hline $\mathrm{T} 3$ & 14 & \\
\hline $\mathrm{T} 4$ & 81 & \\
\hline Unknown & 5 & \\
\hline \multicolumn{3}{|l|}{ Lymph node } \\
\hline \multicolumn{3}{|l|}{ metastasis } \\
\hline No & 67 & \\
\hline $\mathrm{NI}$ & 29 & \\
\hline N2 & 13 & \\
\hline Unknown & 6 & \\
\hline \multicolumn{3}{|l|}{ Distant metastasis } \\
\hline Yes & 4 & \\
\hline No & 105 & \\
\hline Unknown & 6 & \\
\hline \multicolumn{3}{|l|}{ TNM stage } \\
\hline I & 12 & \\
\hline II & 54 & \\
\hline III & 39 & \\
\hline IV & 6 & \\
\hline Unknown & 4 & \\
\hline
\end{tabular}

Abbreviation: CRC, colorectal cancer.

from normal controls was 0.541 (95\% CI: $0.465-0.617)$, with a sensitivity of $78.3 \%$ and a specificity of $29.9 \%$ (Figure 3A; Table 3). From this result, we can see that the diagnostic capacity of IGFBP7 seemed better than CEA. When combined with IGFBP7 and CEA, we acquired an AUC of 0.815 (95\% CI: 0.755-0.875) with a sensitivity/specificity of $99.1 \% / 57.9 \%$ (Figure 3A; Table 3). When assessing the diagnostic capabilities of IGFBP7 and CEA in early-stage CRC using the same cut-off value, we observed similar results to all-stage CRC (Figure 3B, Table 3).

\section{Correlation Between Serum Concentration of IGFBP7 and Clinicopathological Features}

The relationships of the levels of serum IGFBP7 and clinicopathological features were showed in Table 4. In our experiment, there were no statistically significant associations between positive rate of IGFBP7 and clinical data, including age, gender, size of tumor, depth of tumor invasion, lymph node status, histological grade, and early-stage or advanced-stage of CRC $(P>0.05)$.

\section{Discussion}

The insulin-like growth factor (IGF) family consists of IGFs, IGF receptors, and IGF-binding proteins (IGFBPs). ${ }^{24-26}$ IGFBP7, also known as IGFBP-rP1, is a member of the IGF family. IGFBP7 is a protein encoded by the IGFBP7 gene. ${ }^{27,28}$ The main function of this protein is to regulate the availability of IGFs in tissue and modulate IGF binding to its receptors. IGFBP7 binds to IGF with high affinity. ${ }^{29}$ In addition, research has found that IGFBP7 stimulates cell adhesion and is associated with some cancers. ${ }^{30}$ For example, overexpression of IGFBP7 is associated with tumor progression and poor survival in gastric cancer (GC). It is suggested that IGFBP7 may play a role in tumor progression of GC. ${ }^{31}$ Smith et $\mathrm{al}^{32}$ reported that DNA methylation in the IGFBP7 promoter was associated with transcriptional silencing in esophageal adenocarcinoma (EAC), and this silencing was usually observed in EAC tissues. Patients with methylated IGFBP7 often have better survival rates. This result indicates that IGFBP7 plays a role in tumor progression in adenocarcinoma. Research on CRC showed that when IGFBP7 is expressed by the tumor cells themselves, IGFBP7 can promote the anchored independent growth of malignant mesenchymal cells and epithelial cells with an EMTphenotype in addition to its tumor-suppressor function. ${ }^{33}$ However, serum IGFBP7 has not been detected in CRC patients whether it is up-regulated or down-regulated. Therefore, in this study, we tried to detect circulating IGFBP7 in CRC using ELISA. 


$4.7048-4.8900$
$4.5196-4.7048$
$4.3344-4.5186$
$4.1492-4.3344$
$3.8640-4.1492$
$3.7788-3.9640$
$3.5936-3.7788$
$3.4084-3.5936$
$3.2232-3.4084$
$3.0380-3.2232$
$2.8528-3.0380$
$2.6676-2.8528$
$2.4824-2.6676$
$2.2972-2.4824$
$2.1120-2.2972$
$1.9268-2.1120$
$1.7416-1.8268$
$1.5564-1.7416$
$1.3712-1.5564$
$1.1860-1.3712$
$1.0008-1.1860$
$0.8156-1.0008$
$0.6304-0.8156$
$0.4452-0.6304$
$0.2600-0.4452$

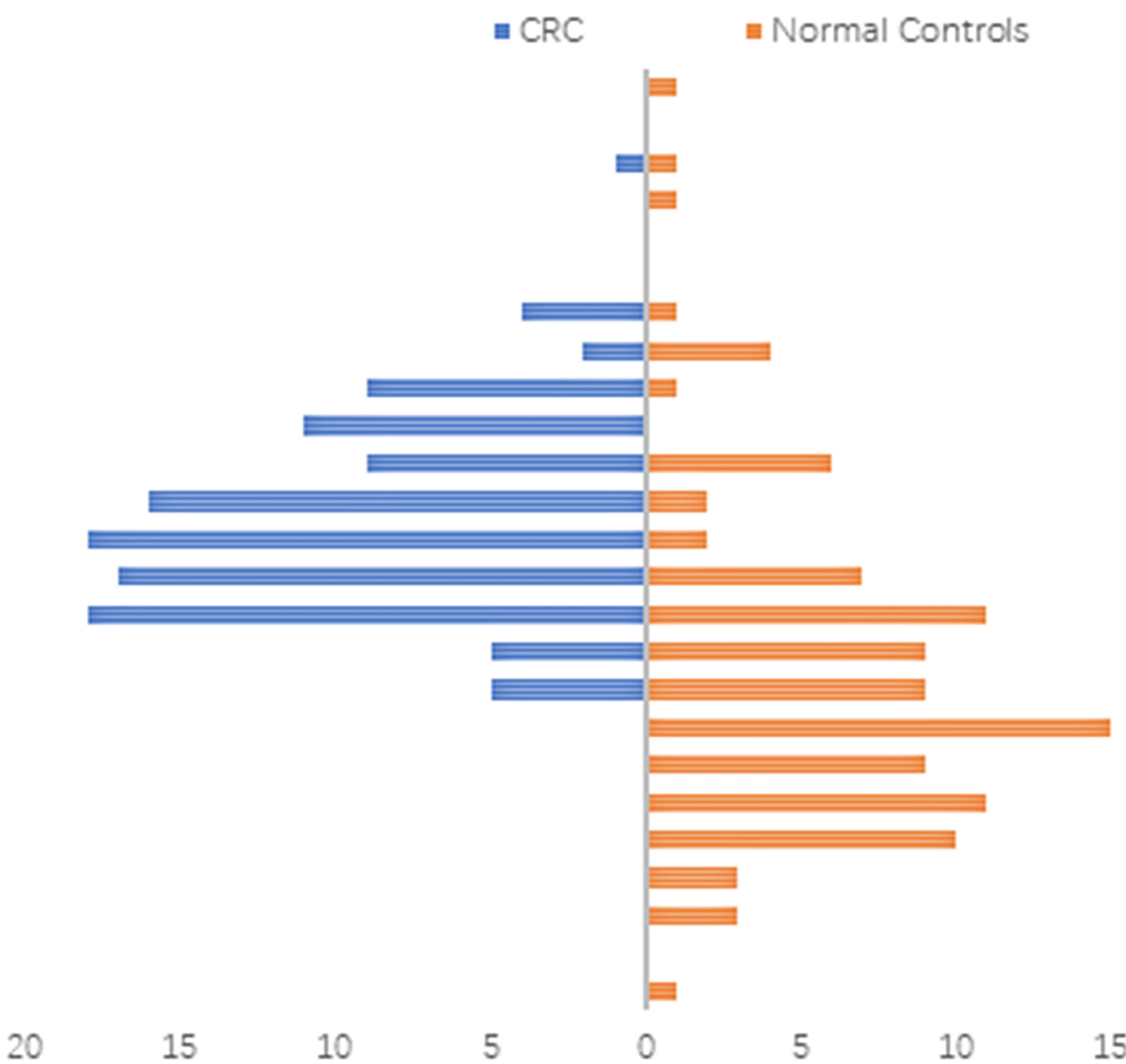

Figure I A distribution bar charts of the predicted probability of IGFBP7 in CRC and normal controls. The lowest concentration was $0.26 \mathrm{ng} / \mathrm{mL}$ and the highest one was $4.89 \mathrm{ng} / \mathrm{mL}$. The predicted probability was divided equally for 25 sections and the diagram of CRC is in blue and normal control is in orange. CRC accounts for more histogram volume on higher concentration while normal groups for more lower concentration.

In this study, the levels of serum IGFBP7 were significantly increased in patients with CRC and early-stage CRC compared with healthy controls. Serum IGFBP7 performed a diagnostic value in CRC with AUC of 0.815 , sensitivity of $93.9 \%$ and specificity of $64.5 \%$. CEA is currently the most widely studied tumor marker for CRC. ${ }^{5,11,34}$ Therefore, in this study, we also explored the diagnostic efficacy of CEA for CRC. As for the CEA, it demonstrated AUC values of 0.541, associated with $78.3 \%$ sensitivity and $29.9 \%$ specificity. In CRC,

Table 2 Comparison Between Three Groups

\begin{tabular}{|l|l|l|l|}
\hline & N & $\begin{array}{l}\text { Serum IGFBP7 } \\
\text { Expression }\end{array}$ & \multirow{2}{*}{ P value* } \\
\cline { 3 - 3 } & & Mean \pm SD & \\
\hline CRC & 115 & $2.679 \pm 0.480$ & $<0.001$ \\
Early-stage CRC $(0+1+$ II) & 24 & $2.683 \pm 0.417$ & $<0.001$ \\
Normal controls & 107 & $1.932 \pm 0.820$ & \\
\hline
\end{tabular}

Notes: *Compared with normal controls.
IGFBP7 had much higher sensitivity than CEA to detect $\mathrm{CRC}$ at the time of diagnosis, and its specificity was also higher to that of CEA. Therefore, compared with CEA, IGFBP7 has a higher diagnostic ability, which can distinguish patients with CRC from patients without cancer. In fact, the primary objective of this study was to assess the ability of IGFBP7 to detect early-stage CRC. In the earlystage CRC, serum IGFBP7 performed a diagnostic value with AUC of 0.826 (95\% CI:0.757-0.896), sensitivity of $95.8 \%$ and specificity of $64.5 \%$. Moreover, the AUC measured by CEA in early-stage CRC patients was 0.545 (95\% CI: $0.421-0.669$ ), with a sensitivity of $79.2 \%$ and a specificity of $29.9 \%$. Thus, compared with CEA, IGFBP7 also improved the diagnostic performance of early-stage CRC. These findings highlighted the potential of IGFBP7 as a non-invasive assessment for CRC at the early stage.

A few studies have explored the potential of serum IGFBP7 as a biomarker for malignant tumors. ${ }^{20,21,35}$ Consistent with the results of this study, high expression 


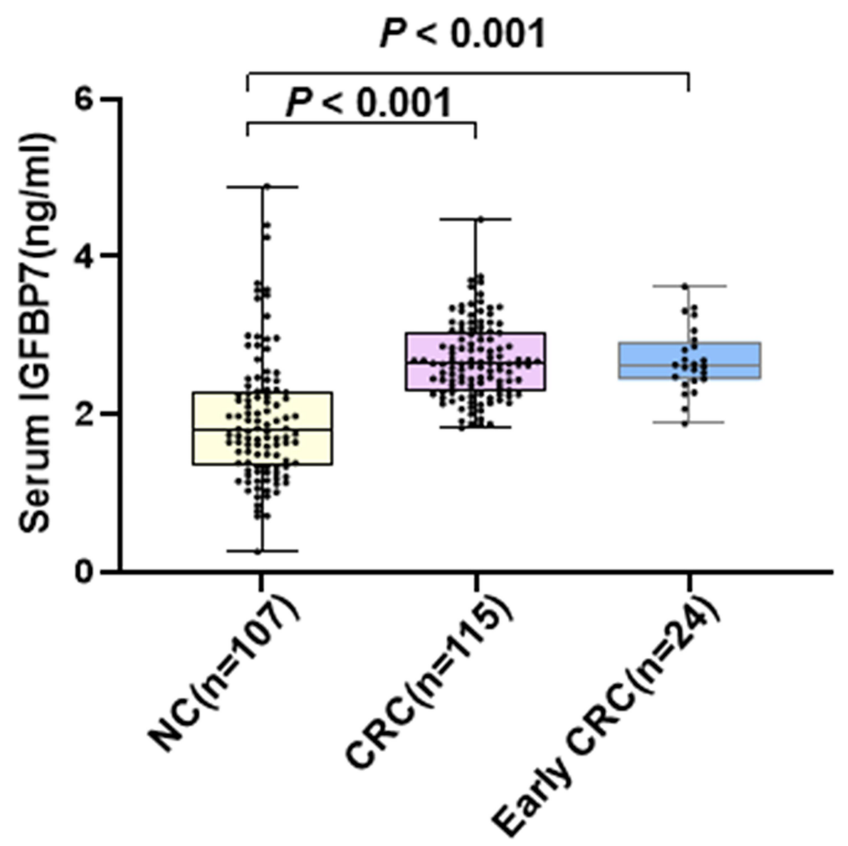

Figure 2 The concentration of IGFBP7 in serum of patients and normal subjects was measured by enzyme-linked immunosorbent assay (ELISA). The concentration of serum IGFBP7 of every sample in three groups were shown in scatter plot and box plot. The lines in the box are means.

of IGFBP7 is positively correlated with cancer. In our previous study, serum IGFBP7 levels were measured by ELISA in 107 normal and 106 ESCC patients. The results showed that it achieved the AUC of 0.794 for ESCC and 0.725 for early-stage ESCC. ${ }^{20}$ Another study performed by Liu et al also demonstrated that IGFBP7 provided high diagnostic accuracy with AUCs of 0.800 in EJA and 0.721 in early-stage EJA, respectively. ${ }^{21}$ These findings suggested that serum IGFBP7 might be a marker for the
Table 3 The ROC Curve Assay of IGFBP7, CEA and a Combination of IGFBP7 and CEA

\begin{tabular}{|l|l|l|l|}
\hline Variables & AUC $(\mathbf{9 5 \%}$ CI) & $\begin{array}{l}\text { Sensitivity } \\
\text { (\%) }\end{array}$ & $\begin{array}{l}\text { Specificity } \\
\text { (\%) }\end{array}$ \\
\hline $\begin{array}{l}\text { CRC vs NC } \\
\text { IGFBP7 }\end{array}$ & $0.815(0.754-0.877)$ & 93.9 & 64.5 \\
CEA & $0.541(0.465-0.617)$ & 78.3 & 29.9 \\
IGFBP7+CEA & $0.815(0.755-0.875)$ & 99.1 & 57.9 \\
\hline Early stage & & & \\
CRC vs NC & & & \\
IGFBP7 & $0.826(0.757-0.896)$ & 95.8 & 64.5 \\
CEA & $0.545(0.421-0.669)$ & 79.2 & 29.9 \\
IGFBP7+CEA & $0.829(0.758-0.899)$ & 95.8 & 57.9 \\
\hline
\end{tabular}

Abbreviations: AUC, area under the curve; $95 \% \mathrm{Cl}, 95 \%$ confidence interval; CRC, colorectal cancer; NC, normal controls.

diagnosis of gastrointestinal cancer. However, testing serum IGFBP7 alone could not meet the requirements of clinical practice. Studies have shown that compared with a single biomarker, the combined detection of multiple serum proteins would increase the sensitivity or specificity of CRC. ${ }^{34,36}$ For example, Zhang et al found that the combined use of CEA and CA19-9 could improve the diagnosis rate of $\mathrm{CRC}$ and increase its sensitivity from $47.8 \%$ to $71.7 \%{ }^{37}$ For CRC, two studies showed that the combinations of CEA + CA72-4 or CEA + CA72-4 + CA19-9 increased AUC from 0.75 (with the best single marker) to 0.80 and 0.81 , respectively. ${ }^{38,39}$ In our experiment, when we combined with IGFBP7 and CEA, the diagnostic value of AUC was $0.815 \quad(95 \%$ CI:0.755-0.875), the sensitivity was $99.1 \%$ and the
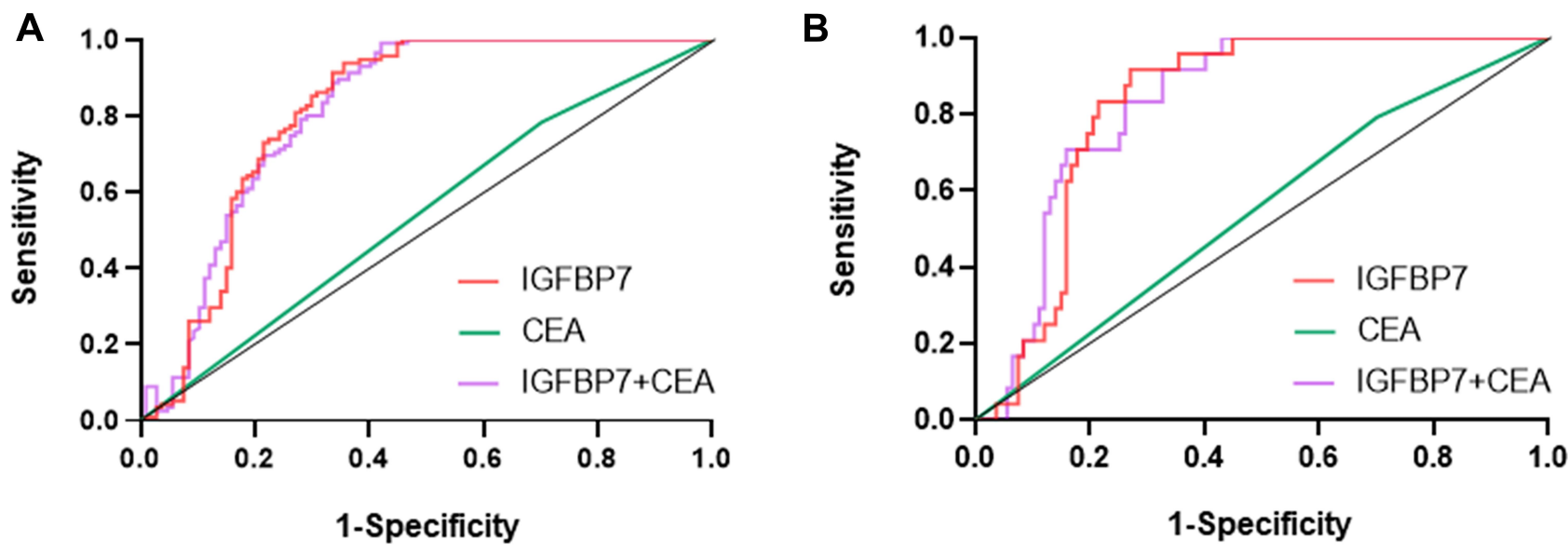

Figure 3 Receiver operating characteristic (ROC) curve analysis in the diagnosis of CRC and early-stage CRC. Three groups versus NC group are in different colors. (A) The performance of the IGFBP7, CEA, or the combination of IGFBP7 and CEA in distinguishing CRC from normal controls. (B) The performance of the IGFBP7, CEA, or the combination of IGFBP7 and CEA in distinguishing early-stage CRC from normal controls. The area under the block line is 0.5 , for reference.

Abbreviation: $\mathrm{CRC}$, colorectal cancer. 
Table 4 Relationship Between Positive Rates of IGFBP7 and Clinicopathologic Features in CRC Patients

\begin{tabular}{|c|c|c|c|c|c|}
\hline & $\mathbf{n}$ & Positive & $\%$ & $\chi^{2}$ & $P$ value \\
\hline \multicolumn{6}{|l|}{ Patient age } \\
\hline$<63$ & 45 & 42 & 93.3 & 0.010 & 0.922 \\
\hline$\geq 63$ & 70 & 65 & 92.9 & & \\
\hline \multicolumn{6}{|l|}{ Gender } \\
\hline Male & 47 & 43 & 91.5 & 0.589 & 0.714 \\
\hline Female & 68 & 64 & 94.1 & & \\
\hline \multicolumn{6}{|l|}{ Tumor size } \\
\hline$<5$ & 49 & 45 & 91.8 & 0.499 & 0.779 \\
\hline$\geq 5$ & 61 & 57 & 93.4 & & \\
\hline Unknown & 5 & 5 & 100 & & \\
\hline \multicolumn{6}{|l|}{ Histological grade } \\
\hline High(gradel) & I & I & 100 & 0.366 & 0.947 \\
\hline Middle(grade2) & 92 & 85 & 92.4 & & \\
\hline Low(grade3) & 1 & 1 & 100 & & \\
\hline Unknown & 21 & 20 & 95.2 & & \\
\hline \multirow{2}{*}{\multicolumn{6}{|c|}{$\begin{array}{l}\text { Depth of tumor } \\
\text { invasion }\end{array}$}} \\
\hline & & & & & \\
\hline TI & 2 & 2 & 100 & 1.852 & 0.763 \\
\hline $\mathrm{T} 2$ & 13 & 13 & 100 & & \\
\hline T3 & 14 & 13 & 92.9 & & \\
\hline $\mathrm{T} 4$ & 81 & 74 & 91.4 & & \\
\hline Unknown & 5 & 5 & 100 & & \\
\hline \multicolumn{6}{|l|}{ Lymph node metastasis } \\
\hline No & 67 & 61 & 91.0 & 4.457 & 0.216 \\
\hline $\mathrm{NI}$ & 29 & 29 & 100 & & \\
\hline N2 & 13 & 11 & 84.6 & & \\
\hline Unknown & 6 & 6 & 100 & & \\
\hline \multicolumn{6}{|l|}{ Distant metastasis } \\
\hline Mo & 105 & 97 & 92.4 & 0.819 & 0.664 \\
\hline MI & 4 & 4 & 100 & & \\
\hline Unknown & 6 & 6 & 100 & & \\
\hline \multicolumn{6}{|l|}{ TNM stage } \\
\hline Early stage $(0+|+| \mid A)$ & 24 & 23 & 95.8 & 0.952 & 0.621 \\
\hline $\begin{array}{l}\text { Advanced stage (IIB } \\
+ \text { III+IV) }\end{array}$ & 85 & 78 & 91.8 & & \\
\hline Unknown & 6 & 6 & 100 & & \\
\hline
\end{tabular}

specificity was $57.9 \%$. The results showed that the sensitivity of IGFBP7 + CEA to detect CRC was higher than that of IGFBP7. Similar results were observed in the earlystage CRC. Thus, we hope that IGFBP7 can be combined with some established tumor markers (such as CEA, CA72-4, CA19-9) to further improve the diagnostic efficacy of CRC. At present, the examination of CRC still mainly relies on endoscopy. ${ }^{8}$ If IGFBP7 is used as a screening tool for $\mathrm{CRC}$, it can also be used in combination with endoscopy, which may help improve the diagnosis rate of early-stage CRC.

Studies have shown that fasting blood glucose in CRC patients is positively correlated with the expression of IGFBP7 in CRC tissues. It suggests that IGFBP7 may be a gene involved in the occurrence and development of type 2 diabetes. Type 2 diabetes is a disease caused by insulin resistance and insulin secretion defects. An important cause of type 2 diabetes is the weakened effect of insulin on adipose tissue, skeletal muscle, and liver. Therefore, insulin resistance is an important feature of type 2 diabetes. Our research on the relationship between IGFBP7 and insulin resistance helps us understand the role of IGFBP7 in insulin resistance, diabetes, and metabolic syndrome. Therefore, we explored the relationship between the level of peripheral blood IGFBP7 and type 2 diabetes and found that the expression of IGFBP7 with diabetes (18) and without diabetes (97) in more than 115 cases of CRC was not statistically significant (Supplementary Figure 1). The reason for this phenomenon may be that CRC patients only draw blood on an empty stomach in the morning without monitoring their blood glucose. Therefore, abnormal blood glucose in some CRC patients may be ignored and affect the final result.

As for the relationship between serum IGFBP7 and the clinical data of CRC, no significant association was found (all $P>0.05$ ). Since the age of cancer patients and healthy controls were not well matched, further research could be performed with corresponding age. Our study was single and the sample size is small, which may lead to bias. But to our knowledge, this is the first time that the diagnostic value of serum IGFBP7 for early-stage CRC has been reported. We believe that if large sample studies are conducted in multiple institutions, our research will significantly improve the ability to assess the serum CRC of IGFBP7. This is the direction we need to work on in the future.

\section{Conclusion}

In conclusion, our results suggest that IGFBP7 might be a potential serum biomarker for the diagnosis of CRC, although these results must be confirmed in larger samples and in different populations.

\section{Acknowledgments}

We thank the reviewers for critical comments. 


\section{Funding}

This work was supported by grants from the National Natural Science Foundation of China $(81,871,921)$; the Natural Science Foundation of Guangdong Province Outstanding Youth Project (2019B151502059) and the Basic \& Applied Basic Research Programs of Guangdong province (2018KZDXM033).

\section{Disclosure}

The authors report no conflicts of interest in this work.

\section{References}

1. Bray F, Ferlay J, Soerjomataram I, et al. Global cancer statistics 2018: GLOBOCAN estimates of incidence and mortality worldwide for 36 cancers in 185 countries. CA Cancer J Clin. 2018;68 (6):394-424. doi:10.3322/caac.21492

2. Chen W, Sun K, Zheng R, et al. Cancer incidence and mortality in China, 2014. Chin J Cancer Res. 2018;30(1):1-12. doi:10.21147/j. issn.1000-9604.2018.01.01

3. Siegel RL, Miller KD, Fedewa SA, et al. Colorectal cancer statistics, 2017. CA Cancer J Clin. 2017;67(3):177-193. doi:10.3322/caac.21 395

4. Cespedes Feliciano EM, Kroenke CH, Meyerhardt JA, et al. Metabolic dysfunction, obesity, and survival among patients with early-stage colorectal cancer. J Clin Oncol. 2016;34(30):3664-3671. doi:10.1200/JCO.2016.67.4473

5. Yoruker EE, Holdenrieder S, Gezer U. Blood-based biomarkers for diagnosis, prognosis and treatment of colorectal cancer. Clin Chim Acta. 2016;455:26-32. doi:10.1016/j.cca.2016.01.016

6. Karbownik M, Brzezianska E, Lewinski A. Increased expression of mRNA specific for thymidine kinase, deoxycytidine kinase or thymidine phosphorylase in human papillary thyroid carcinoma. Cancer Lett. 2005;225(2):267-273. doi:10.1016/j.canlet.2004.10.044

7. He Q, Zou L, Zhang PA, et al. The clinical significance of thymidine kinase 1 measurement in serum of breast cancer patients using Anti-TK1 antibody. Int J Biol Markers. 2000;15(2):139-146. doi:10. 1177/172460080001500203

8. de Jesus Leite MAF, Puga GM, Arantes FJ, et al. Effects of combined and resistance training on the inflammatory profile in breast cancer survivors: a systematic review. Complement Ther Med. 2018;36:73-81. doi:10.1016/j.ctim.2017.11.023

9. Nisman B, Allweis T, Kadouri L, et al. Comparison of diagnostic and prognostic performance of two assays measuring thymidine kinase 1 activity in serum of breast cancer patients. Clin Chem Lab Med. 2013;51(2):439-447. doi:10.1515/cclm-2012-0162

10. Duffy MJ. Role of tumor markers in patients with solid cancers: a critical review. Eur J Intern Med. 2007;18(3):175-184. doi:10.1016/j.ejim.2006.12.001

11. Newton KF, Newman W, Hill J. Review of biomarkers in colorectal cancer. Colorectal Dis. 2012;14:3-17. doi:10.1111/j.1463-1318.20 10.02439

12. Duffy MJ. Carcinoembryonic antigen as a marker for colorectal cancer: is it clinically useful? Clin Chem. 2001;47(4):624-630. doi:10.1093/clinchem/47.4.624

13. Meersch M, Schmidt C, Van Aken H, et al. Urinary TIMP-2 and IGFBP7 as early biomarkers of acute kidney injury and renal recovery following cardiac surgery. PLoS One. 2014;9(3):e93460. doi:10. 1371/journal.pone.0093460

14. Evdokimova V, Tognon CE, Benatar T, et al. IGFBP7 binds to the IGF-1 receptor and blocks its activation by insulin-like growth factors. Sci Signal. 2012;5(255):ra92. doi:10.1126/scisignal.2003184
15. Fujioka S, Matsuzawa Y, Tokunaga K, et al. Contribution of intra-abdominal fat accumulation to the impairment of glucose and lipid metabolism in human obesity. Metabolism. 1987;36(1):54-59. doi:10.1016/0026-0495(87)90063-1

16. Silha JV, Gui YT, Murphy LJ. Impaired glucose homeostasis in insulin-like growth factor-binding protein-3-transgenic mice. $\mathrm{Am}$ J Physiol Endocrinol Metab. 2002;283(5):E937-E945. doi:10.1152/ ajpendo.00014.2002

17. Fontaine KR, Redden DT, Wang C, et al. Years of life lost due to obesity. JAMA. 2003;289(2):187-193. doi:10.1001/jama.289.2.187

18. Wang Z, Wang Z, Liang Z, et al. Expression and clinical significance of IGF-1, IGFBP-3, and IGFBP-7 in serum and lung cancer tissues from patients with non-small cell lung cancer. Onco Targets Ther. 2013;6:1437-1444. doi:10.2147/OTT.S51997

19. Sullivan L, Murphy TM, Barrett C, et al. IGFBP7 promoter methylation and gene expression analysis in prostate cancer. J Urol. 2012;188 (4):1354-1360. doi:10.1016/j.juro.2012.06.002

20. Huang XY, Hong CQ, Peng YH, et al. The diagnostic value of serum IGFBP7 in patients with esophageal squamous cell carcinoma. $J$ Cancer. 2019;10(12):2687-2693. doi:10.7150/jca.32393

21. Liu C-T, Xu Y-W, Guo H, et al. Serum insulin-like growth factor binding protein 7 as a potential biomarker in the diagnosis and prognosis of esophagogastric junction adenocarcinoma. Gut Liver. 2019. doi:10.5009/gnl19135

22. Amin MB, Greene FL, Edge SB, et al. The eighth edition AJCC cancer staging manual: continuing to build a bridge from a population-based to a more "personalized" approach to cancer staging. CA Cancer J Clin. 2017;67:93-99. doi:10.3322/caac.21388

23. Ruopp MD, Perkins NJ, Whitcomb BW, et al. Youden Index and optimal cut-point estimated from observations affected by a lower limit of detection. Biom J. 2008;50(3):419-430. doi:10.1002/ bimj.200710415

24. Khandwala HM, McCutcheon IE, Flyvbjerg A, et al. The effects of insulin-like growth factors on tumorigenesis and neoplastic growth. Endocr Rev. 2000;21:215-244. doi:10.1210/edrv.21.3.0399

25. Pollak M. The insulin and insulin-like growth factor receptor family in neoplasia: an update. Nat Rev Cancer. 2012;12(3):159-169. doi: $10.1038 / \mathrm{nrc} 3215$

26. Kim H-S, Nagalla SR, Oh Y, et al. Identification of a family of low-affinity insulin-like growth factor binding proteins (IGFBPs): characterization of connective tissue growth factor as a member of the IGFBP superfamily. Proc Natl Acad Sci U S A. 1997;94 (24):12981-12986. doi:10.1073/pnas.94.24.12981

27. Murphy M, Pykett MJ, Harnish P, et al. Identification and characterization of genes differentially expressed in meningiomas. Cell Growth Differ. 1993;4:715-722.

28. Yamauchi T, Umeda F, Masakado M, et al. Purification and molecular cloning of prostacyclin-stimulating factor from serum-free conditioned medium of human diploid fibroblast cells. Biochem J. 1994;303(2):591-598. doi:10.1042/bj3030591

29. Oh Y, Nagalla SR, Yamanaka Y, et al. Synthesis and characterization of insulin-like growth factor-binding protein (IGFBP)-7. Recombinant human mac25 protein specifically binds IGF-I and -II. J Biol Chem. 1996;271(48):30322-30325. doi:10.1074/jbc.271.48.30 322

30. Gommans WM, Tatalias NE, Sie CP, et al. Screening of human SNP database identifies recoding sites of A-to-I RNA editing. RNA. 2008;14(10):2074-2085. doi:10.1261/rna.816908

31. Sato Y, Inokuchi M, Takagi Y, et al. Relationship between expression of IGFBP7 and clinicopathological variables in gastric cancer. J Clin Pathol. 2015;68(10):795-801. doi:10.1136/jclinpath-2015202987

32. Smith E, Ruszkiewicz AR, Jamieson GG, et al. IGFBP7 is associated with poor prognosis in oesophageal adenocarcinoma and is regulated by promoter DNA methylation. Br J Cancer. 2014;110(3):775-782. doi:10.1038/bjc. 2013.783 
33. Rupp C, Scherzer M, Rudisch A, et al. IGFBP7, a novel tumor stroma marker, with growth-promoting effects in colon cancer through a paracrine tumor-stroma interaction. Oncogene. 2015;34: 815-825. doi: $10.1038 /$ onc. 2014.18

34. Wild N, Andres H, Rollinger W, et al. A combination of serum markers for the early detection of colorectal cancer. Clin Cancer Res. 2010;16(24):6111-6121. doi:10.1158/1078-0432.CCR-10-0119

35. Benassi MS, Pazzaglia L, Novello C, et al. Tissue and serum IGFBP7 protein as biomarker in high-grade soft tissue sarcoma. Am J Cancer Res. 2015;5:3446-3454.

36. Chan CC, Fan CW, Kuo YB, et al. Multiple serological biomarkers for colorectal cancer detection. IJC. 2010;126:1683-1690. doi:10.10 02/ijc. 24912
37. Zhang SY, Lin M, Zhang HB. Diagnostic value of carcinoembryonic antigen and carcinoma antigen19-9 for colorectal carcinoma. Int J Clin Exp Pathol. 2015;8:9404-9409. doi:10.1159/000480247

38. Carpelan-Holmström M, Louhimo J, Stenman U-H, et al. Estimating the probability of cancer with several tumor markers in patients with colorectal disease. Oncology. 2004;66:296-302. doi:10.1159/000 078330

39. Carpelan-Homström M, Louhimo J, Stenman U-H, et al. CEA, CA 19-9 and CA 72-4 improve the diagnostic accuracy in gastrointestinal cancers. Anticancer Res. 2002;22:2311-2316.

\section{Publish your work in this journal}

OncoTargets and Therapy is an international, peer-reviewed, open access journal focusing on the pathological basis of all cancers, potential targets for therapy and treatment protocols employed to improve the management of cancer patients. The journal also focuses on the impact of management programs and new therapeutic

Submit your manuscript here: https://www.dovepress.com/oncotargets-and-therapy-journ agents and protocols on patient perspectives such as quality of life, adherence and satisfaction. The manuscript management system is completely online and includes a very quick and fair peer-review system, which is all easy to use. Visit http://www.dovepress.com/ testimonials.php to read real quotes from published authors. 